\title{
Encontros, Laços e Vidas: o acompanhamento no CAPS
}

Meetings, Ties and Lives: the follow-up in CAPS

Cíntia Moreira de Souza Fraga ${ }^{1}$ e Ademir Pacelli Ferreira ${ }^{2}$

\section{Introdução}

A reforma psiquiátrica é "a tentativa de dar ao problema da loucura, outra resposta social"1. Como em outras partes do mundo, no pós-guerra mundial, com a abertura democrática, também as condições dos doentes mentais foram questionadas. Os terríveis campos de concentração espelharam as condições dos hospícios. Vários foram os movimentos de transformação desta realidade. Também no Brasil, algumas tentativas foram feitas. Mas com o fechamento político da ditadura e com a sua política hegemônica de privatização da assistência restou basicamente o trabalho pioneiro de Nise da Silveira, o Centro Psiquiátrico Pedro II, onde criou um Setor de atividades criativas e expressivas, inovou a assistência e a compreensão da psicose. Depois, com a Casa das Palmeiras, espaço externo ao hospício para o acompanhamento dos chamados esquizofrênicos, ela abriu novos horizontes terapêuticos.

Nos finais da década de setenta os trabalhadores em saúde mental conseguiram se organizar e iniciar uma luta contra a degradação e a violência nos hospícios. Com a falência financeira do sistema de saúde, o estado foi obrigado a empreender a reforma da saúde. Nesta esteira surgiu o projeto da reforma psiquiátrica brasileira, em que as lideranças puderam levar para o ministério as diretrizes elaboradas pelas lutas empreendidas pelos profissionais. $\mathrm{O}$ eixo deste projeto está centrado na diminuição das internações, no esvaziamento dos asilos e no privilégio da assistência externa ao hospício. Portanto, visa resgatar o sujeito com transtornos mentais do isolamento para que este possa desenvolver o sentimento de pertinência social, desfrutar de suas interações e participar do convívio da vida em comum. Para tal, vêm sendo

\section{Resumo}

Este trabalho visa apresentar algumas reflexões sobre a criação do dispositivo terapêutico Centro de Atenção Psicossocial (CAPS). Parte-se da experiência de estágio em projeto de extensão no Hospital Dia (HD) da Unidade de Psiquiatria e em sua posterior transição em CAPS, pontuando alguns elementos desta transição. Apresenta-se o acompanhamento terapêutico de uma frequentadora nesta transição, para ilustrar alguns elementos desta mudança. Indica-se alguns elementos para refletir sobre a questão da institucionalização e desinstitucionalização nos novos dispositivos de saúde mental no Brasil. Finalmente, pontua-se a importância da formação de profissionais para o avanço das políticas de transformação das práticas em saúde mental.

Palavras-chaves: Atenção Psicossocial; Desinstitucionalização; Projeto Terapêutico; Caso Clínico

Área Temática: Saúde

Linha de Extensão: Saúde Humana 
criados centenas de novos dispositivos de cuidado em saúde mental. Destes, os Centros de Atenção Psicossocial (CAPS) passaram a ser a principal referência.

Fruto da experiência de prática junto aos CAPS, o presente artigo reflete sobre este lugar de assistência e de formação dentro da universidade. No programa em questão, o estagiário se insere na equipe e participa das oficinas terapêuticas, da supervisão especializada, reuniões clínico-institucionais e do acompanhamento terapêutico dos frequentadores do setor. A escrita do caso é feita a partir da relação do estagiário e da equipe com o frequentador, em que o processo subjetivo é acompanhado através de falas, intervenções, registros em ata dos acontecimentos e das atividades diárias, além das observações clínicas.

Foucault ${ }^{2}$ indicou em sua pesquisa, História da Loucura na Idade Clássica, que a loucura teve diversas representações sociais antes de ser abordada pela racionalidade da medicina. Assinalaremos aqui alguns elementos desta primeira especialidade médica e de seu objeto: a loucura. A experiência na atual modalidade assistencial será situada dentro do chamado Movimento da Reforma Psiquiátrica Brasileira, em que o termo saúde mental substitui a designação de doença mental, por esta ter implicações e representações sociais mais negativas.

\section{A Reforma Psiquiátrica no Brasil e o viés da saúde}

Além de influências da França, Inglaterra e Estados Unidos, a nossa reforma psiquiátrica teve grande espelhamento na Psiquiatria Democrática italiana liderada por Franco Basaglia, ao propor desconstruir o modelo centrado no hospital psiquiátrico, de caráter asilar, para construir um novo modelo de cuidado e atenção à pessoa com sofrimento psíquico grave.

Observou-se que o asilamento e as condições às quais os pacientes eram submetidos nas longas internações, contribuíam para a sua maior alienação mental e social ao impedir a construção de vínculos. Com o propósito de resgatar a cidadania e a dignidade dessas pessoas, priorizou-se um tratamento mais humanizado que possibilitasse a reinserção do indivíduo com sofrimento mental em sua comunidade através da criação de laços sociais. Um paradigma que passa a entender o psicopatológico como um estado existencial de sofrimento psíquico e não como uma mera doença a ser extraída.

As diretrizes estabelecidas na III Conferência Nacional de Saúde Mental ${ }^{3}$ postularam a necessidade de garantir relações que potencializassem a subjetividade, a autoestima, a autonomia e a cidadania do sujeito. Para tal, foram propostas ações que permitissem a inclusão social, favorecendo o convívio desses indivíduos com diferentes pessoas e, consequentemente, a necessidade de transformações da sociedade para aceitar e conviver com a diferença ${ }^{4}$.

O suporte da Lei 10.216 , de 06/04/015, que dispõe sobre a proteção e os direitos das pessoas portadoras de transtornos mentais e redireciona o modelo assistencial em saúde mental e a Portaria/ $\mathrm{GM} \mathrm{n}^{\circ} 336$, de $19 / 02 / 02^{6}$, que define e estabelece diretrizes para o funcionamento dos Centros de Atenção Psicossocial, respaldou o desenvolvimento das práticas de transformação da realidade assistencial brasileira em saúde mental através da criação de serviços substitutivos ao hospital psiquiátrico, tais como as redes de atenção à saúde mental, os centros de atenção psicossocial, as residências terapêuticas, os leitos psiquiátricos em hospitais gerais, entre outros.

\section{O Dispositivo CAPS ou Centro de Atenção Psicossocial}

O primeiro Centro de Atenção Psicossocial do Brasil foi inaugurado em março de 1986, na cidade de São Paulo. A partir disso, inúmeros outros serviços foram criados no país e hoje os CAPS constituem-se como referência assistencial para os transtornos psíquicos graves?

Os CAPS são mantidos com recursos da descentralização do SUS, que repassa aos municípios os recursos para a assistência em saúde. As áreas programáticas devem constituir-se articuladas na referência do território. Não como mera área geográfica, mas sim, como postula o Ministério da Saúde ${ }^{8}$, com a participação,

(...) das pessoas, das instituições, das redes e dos cenários nos quais se dão a vida comunitária. (...) Trabalhar no território significa assim resgatar todos os saberes e potencialidades dos recur- 
sos da comunidade, construindo coletivamente as soluções, a multiplicidade de trocas entre as pessoas e os cuidados em saúde mental (...)

O CAPS é a unidade ou dispositivo central para a realização dos princípios da Reforma. Como o caracteriza Leal e Delgado ${ }^{9}$, o CAPS é um:

(...) dispositivo estratégico da atual política pública de assistência à saúde mental (...) tem como desafio central a desinstitucionalização (...) O CAPS deve ser entendido também e principalmente como um modo de operar o cuidado e não como um mero estabelecimento de saúde.

Mas como todo sistema assistencial os CAPS enfrentam muitas dificuldades de recursos, de pessoal qualificado e de suporte na construção da rede. Como afirma Amarante, "um CAPS não deveria ser apenas um serviço novo, mas um 'serviço inovador', isto é, espaço de produção de novas práticas sociais para lidar com a loucura e o sofrimento psíquico" ${ }^{10}$.

\section{Do Hospital-Dia ao CAPS}

O Hospital-Dia foi criado no ano de 1993, através do trabalho de professores, técnicos e residentes ligados à Unidade Docente Assistencial (UDA) de Psiquiatria, com o objetivo de criar um espaço entre o ambulatório e a enfermaria de acompanhamento dos egressos com transtornos graves e de longa duração. Foi cadastrado como projeto geral de extensão, sendo que outros projetos de extensão foram aí desenvolvidos.

Desta forma, o HD manteve o papel do hospital universitário, ou seja, o de assistência, formação e pesquisa, ampliando o trabalho que antes só contava com o ambulatório e a enfermaria. O Hospital-Dia pode ser considerado como um desdobramento do projeto que vinha sendo desenvolvido na enfermaria desde 1979.

A mudança do HD para o CAPS tinha como meta implantar práticas universitárias articuladas com a rede pública de serviços de saúde mental, o que implicava na construção de um dispositivo de assistência afinado com os princípios da reforma. No HD isso não era mais possível, pois este serviço, além da situação precária de sua estrutura física, não recebia recursos para compra de materiais necessários a sua manutenção e ao desenvolvimento de suas terapêuticas.

A partir da construção de várias parcerias com unidades universitárias, complexo hospitalar universitário e gestão técnica e assistencial, foi instituído o CAPS. Este foi estabelecido em conformidade com as características de um CAPS II, funcionando das nove às dezessete horas, de segunda a sexta-feira, contando com várias oficinas terapêuticas, através de recursos expressivos, grupais, corporais, ritmos, convivência e geração de renda.

Além do acompanhamento diário dos frequentadores e das oficinas terapêuticas, os familiares também são atendidos através de reuniões e entrevistas. Um espaço para a criação de diálogo que favoreça a elaboração de conflitos e impasses nas relações inter e intrafamiliares.

Realizam-se também assembleias de usuários, familiares e profissionais, com a participação de todos os segmentos que constituem o CAPS. As assembleias constituem-se em um espaço à participação democrática, à avaliação e à sustentação do trabalho realizado no serviço, por meio das trocas entre os diferentes participantes. Essa troca é muito rica, pois gera discussões produtivas para se pensar um melhor desenvolvimento da assistência prestada pelo CAPS.

O programa terapêutico compõe-se de atendimentos individualizados, interconsultas, articulação com a rede interinstitucional, visitas domiciliares, reunião clínico-institucional e participação em Fórum de Saúde Mental de sua Área Programática.

As mudanças não ficaram restritas apenas ao espaço físico; novos profissionais foram contratados para compor o serviço. A equipe atual do CAPS é composta por um psiquiatra, uma enfermeira, duas nutricionistas, duas oficineiras, duas assistentes sociais, duas psicólogas, um técnico de enfermagem, uma terapeuta ocupacional, uma copeira, um técnico administrativo, estagiários e residentes de psicologia, serviço social, enfermagem, supervisor institucional e professores-supervisores clínicos.

A entrada destes profissionais, as parcerias estabelecidas pela equipe inicial com inúmeros parceiros e a entrada de novos frequentadores 
vêm possibilitando significativas alterações no projeto terapêutico de alguns usuários e a criação e introdução de novas propostas de trabalho, o que levou à ampliação de sua meta. É o que indicaremos no caso da frequentadora Maria.

\section{Acompanhamento terapêutico no percurso de Maria}

É sabido que Freud construiu a sua teoria através da articulação entre a experiência clínica e a pesquisa rigorosa. Foi com o estudo dos casos clínicos de suas pacientes histéricas que ele deu início à construção da psicanálise.

Apontando para a importância do estudo de caso, Ferreira ${ }^{11}$ assinala:

Desde o primeiro contato com o paciente, o estudo de caso surge como possibilidade de indicar a direção do tratamento. Para tal, os elementos clínicos que justificaram a internação devem ser traduzidos e transformados à luz da consideração da história do sujeito, para que se possa criar um espaço de acolhida, de fala e de ação, que favoreçam a produção de sentidos e de singularidades.

De forma a garantir as exigências éticas de sigilo, foram alterados o nome e algumas informações sobre história de vida da frequentadora. Maria tem 69 anos, é brasileira, casada e tem dois filhos. Seu pai foi aposentado por problemas psiquiátricos e a sua mãe teria "problemas dos nervos". Embora tenha trabalhado formalmente, não foi aposentada, pois quando iniciou as crises psicóticas abandonou o emprego e a família não procurou de imediato um hospital. Em 1994, Maria começou a apresentar alterações de comportamento, isolando-se, sem vontade de sair da cama e de se alimentar, aparentando semblante triste, ideias de suicídio e comunicação limitada com gestos. Em junho de 2002, Maria começou a falar e agredir verbalmente o seu marido, acusando-o de fraudador e repetindo inúmeras vezes que ele era dono de uma rede de empresas e que desejava prejudicá-la. No primeiro semestre de 2003, Maria compareceu ao ambulatório do HUPE pedindo que fosse realizado um exame de DNA para ela e seus filhos, justificando que este serviria para provar para o seu marido quem ela era. Em outro momento em que nos referimos a este tipo de procura $^{11}$, afirmamos que era como se ela pedisse à medicina genética, que a vinculasse à sua família, desagregada em suas representações e na vida real.

Foi então à Unidade de Psiquiatria e ficou internada à espera de familiares, mas foi inserida no serviço somente no segundo semestre de 2003. Nessa época, Maria mencionava ser uma máquina e que sempre desejava o bem das pessoas. Mencionava, porém, que virou máquina desde que recebeu uma paulada na cabeça, dada pelo marido e dizia ser de metal.

Com a mudança do Hospital-Dia para o CAPS, todos os usuários do Hospital-Dia passaram a constituir o grupo de frequentadores do novo serviço, incluindo Maria. Maria frequenta o CAPS todos os dias, exceto às quintas-feiras pela manhã, quando ocorre a reunião clínico-institucional com toda a equipe técnica do serviço. Desde a sua internação, recebeu o diagnóstico de esquizofrenia, fazendo uso regular de neurolépticos ou antipsicóticos.

O acompanhamento das pessoas que frequentam por muito tempo os dispositivos de atenção psicossociais passa por vários estagiários, já que estes são passageiros. $\mathrm{O}$ estagiário busca o contato através da aproximação e da escuta, sabendo que vai ser sempre um reinício para o frequentador. Neste caso, a primeira aproximação se dá a partir do bazar de vendas das peças produzidas na oficina de geração de renda, em que a coordenadora da atividade introduz a nova estagiária ao grupo que ali estava. Maria, muito simpática e articulada verbalmente, tomou a iniciativa de mostrar as peças, explicar como eram feitas e, ao mesmo tempo, procurava negociá-las.

Além do acompanhamento mais individual, o estagiário geralmente participa de algumas oficinas. Destaca-se aqui a Oficina da Palavra, do Jornal e as reuniões clínicas. A Oficina da $\mathrm{Pa}$ lavra constitui-se num grupo sem número determinado de usuários. $\mathrm{O}$ caráter terapêutico desta oficina encontra-se no espaço que ela abre para a fala. Nela seus participantes podem trazer suas angústias, medos, delírios, alucinações. Já na Oficina de Jornal são produzidos textos e/ou desenhos que deverão ser lidos e discutidos pelo grupo onde o essencial é possibilitar que seja traduzido em desenhos ou palavras aquilo que o usuário estiver disposto a compartilhar com o grupo. As oficinas oferecem um espaço para a troca, o diá- 
logo e a convivência e oferecem o acolhimento e a construção de laços sociais. Visa-se construir com eles um território para o encontro e o compartilhamento de pensamentos, sentimentos e experiências.

No outro encontro, Maria não foi tão simpática como da primeira vez com a estagiária. Talvez o espaço anterior, de comércio, tenha facilitado a aproximação. Já no outro momento surge a raiva pelas perdas anteriores e ela indaga para as estagiárias, "vocês vão ficar mesmo, ou vão sumir como as outras estagiárias?"(sic). Maria valorizava o serviço, seus técnicos e seus frequentadores. Considera a todos como amigos. Diz que ali dentro "as pessoas não tem preconceito, como no lado de fora" (sic). O rodízio de estagiários é vivido como perda, mas também, pela elaboração, há vivência de ganho, pois estes passam a ser testemunhos de sua história.

Maria idealiza o CAPS, pois encontra neste espaço um lugar de afirmação de sua identidade, o que aparece em sua procura inicial desesperada quando veio ao hospital. Neste ambiente encontrou o espaço de acolhimento e escuta para seus delírios e alucinações. Neste ambiente, encontrou também possibilidades de estar em contato com outras pessoas, realizar tarefas novas, falar de seus problemas e preocupações. É bastante solícita e disposta a servir e "ajudar os amigos". Procura saber o que aconteceu se algum frequentador não aparece, demonstrando preocupação e solidariedade. Certa vez escreveu na oficina do Jornal, "me sinto mal e gostaria de melhorar para auxiliar as pessoas nas horas difíceis" (sic). Em outro dia justificou sua falta ao serviço dizendo, "eu precisava ter vindo na semana passada, mas não pude vir devido à gripe que estava, e não podia passar para os outros amigos" (sic).

Estes laços afetivos estão mais restritos ao CAPS e aos familiares. Fora do serviço Maria diz que não tem amigos, relatando que as pessoas acham-na estranha e algumas delas querem o seu mal: "a mulher que fez macumba para mim é culpada pela minha doença. Existem espíritos ruins, que fazem maldade com as pessoas"(sic). Os laços estabelecidos com os outros frequentadores são restritos ao próprio espaço do CAPS.

Maria faz do CAPS o suporte de sua frágil existência. Uma institucionalização necessária para a sua necessidade de ser cuidada. Diz ela, "o CAPS é uma escola, e aqui as pessoas ensinam, são como cuidadoras (...) gostaria de ser cuidada e de cuidar" (sic). Mas alguns elementos de autonomia vão surgindo.

Desde o início da transformação do Hospital-Dia para o CAPS, com suas mudanças físicas e assistenciais, Maria tem participado ativamente de todo esse processo. Esteve presente nas ambientações promovidas pela equipe do HD para familiarizar os frequentadores com o novo espaço, com o novo trajeto, com os novos funcionários. Demonstra bastante entusiasmo pelas novas propostas: os ensaios e a apresentação do desfile de moda e a oficina de produção de bijuterias. Estimulada pela equipe, foi sozinha de sua casa para o local do ensaio, apesar de ter ficado receosa de ir desacompanhada. Costuma sair sozinha somente para ir ao CAPS ou ao hospital. A importância de participar destas novas atividades fica nítida em sua fala: "meu coração está bem, as lembranças boas são coisas que ajudam o coração, assim como fazer mosaico, pulseira" (sic).

Não foram somente nos espaços das oficinas terapêuticas que Maria pôde sentir-se acolhida e ouvida. Na convivência nos ambientes comuns, como a cozinha, os corredores e outros espaços comuns, podemos observar a sua constante interação com outros colegas. São momentos em que relata aos técnicos e estagiários sobre a sua família, a situação de sua comunidade, o motivo de ter faltado no dia anterior. Para Tenório ${ }^{12}$,

(...) a expressão "convivência" ganhou o estatuto de designação de um recurso terapêutico (...) quando se considera que, para além da participação em atendimentos ou oficina, o estar no CAPS foi a "atividade" relevante para o paciente naquele turno.

Estar em tratamento no CAPS não significa que o usuário tenha que se enclausurar dentro dele. Pelo contrário, segundo recomendação do Ministério da Saúde, as propostas de atividades desenvolvidas fora do CAPS devem ser pensadas como "parte de uma estratégia terapêutica de reabilitação psicossocial, que poderá iniciar-se ou ser articulada pelo CAPS, mas que se realizará na comunidade, no trabalho e na vida social" ?.

O acompanhamento terapêutico é uma prática diária do trabalho nos CAPS. Significa acompanhar o frequentador dentro e fora da instituição 
em termos de escuta, cuidado e contribuição para a sua autonomia. Nesse sentido, em outubro de 2009, em uma reunião de equipe, foi indicado para alguns frequentadores um trabalho de acompanhamento terapêutico. Dentre estes usuários estava Maria e, a partir desta data, iniciei com ela este trabalho. Um dos objetivos para este acompanhamento com Maria apontava para a necessidade de favorecer a sua desinstitucionalização.

Como estratégia para se pensar uma proposta de desinstitucionalização para Maria, foi sugerido apoiar a sua iniciativa de oferecer trabalho de manicure inicialmente dentro do CAPS. A função de acompanhante terapêutico estaria dentro da ideia, proposta por Lacan, de "secretário do alienado, que é a de acompanhar o trabalho que o próprio sujeito psicótico já iniciou"13. A estagiária não indicaria a trajetória que Maria deveria seguir, mas iria auxiliá-la durante este trajeto, respeitando a sua singularidade. Visava-se a mediação entre o tratamento dela e o trabalho de manicure dentro do CAPS, para que ela pudesse se colocar para além do papel de doente e sair um pouco desta posição de paciente, de objeto, ou seja, de alguém que precisa ser cuidado pelo outro. Esta função de acompanhante pode ser vista como a de um testemunho, que sustenta um lugar e uma referência para que os acontecimentos tomem forma e existência.

Maria havia sinalizado sobre a importância que a realização de atividades tem para ela. Dizia, "ficar parada não ajuda, me sinto mal quando fico muito tempo parada". "Para estar bem de saúde é bom fazer atividades". "Quero aprender a fazer novas atividades relacionadas ao trabalho no CAPS" (sic).

No início do acompanhamento, perguntou-se a Maria se ela tinha interesse em oficializar o seu trabalho de manicure dentro do CAPS e qual seria a importância deste para ela. Disse que gosta de fazer unha porque "é uma terapia". Ela gosta de ajudar os amigos, mesmo que não paguem nada. Neste mesmo dia estipulou o preço que iria cobrar pelo seu serviço. Foi feita com ela a lista de materiais necessários e, no outro dia, ela foi com a estagiária fazer as compras. Tinha sido decidido na equipe que o CAPS iria garantir a primeira compra e depois, com o que recebesse, ela se responsabilizaria pelos mesmos. Bucava-se, desta maneira, garantir que o trabalho fosse iniciado, permitindo-se, contudo, que ela se apro- priasse da manutenção de seu trabalho. Na farmácia, Maria se saiu muito bem, escolheu tudo que precisava, solicitou a ajuda da balconista para achar o removedor de esmalte, que não estava em nenhuma prateleira. Sua única dificuldade surgiu na hora de lidar com o dinheiro. Nesta hora pediu ajuda. Mais tarde, na oficina, ela propôs que os estagiários pudessem auxiliar os frequentadores a lidar com o dinheiro (valor, troco).

Maria disse que "antes da crise"(sic) exercia atividade de manicure em sua residência. Conta que depois da crise ela parou de fazer unha por causa das tremedeiras (efeito dos neurolépticos e também seus trejeitos) e que não se sentia bem com a presença de pessoas em sua casa, pois segundo ela, estas ficavam "reparando" em tudo e isso fazia lhe mal (suspeitas de fazerem mal a ela, bruxaria, macumba). Ela sempre demonstrava bastante preocupação com o futuro dos filhos e com a situação financeira da família. Diz, "o que tem dado trabalho em relação aos filhos é o desemprego". Também se preocupa com a situação de violência constante na comunidade onde mora. Dizia, "estou bem por estar aqui, mas estou preocupada com o tiroteio que está acontecendo perto de minha casa, com a violência" (sic). Queixa-se também de sua angústia em relação aos tremores que sente nas pernas, sua constante dor de cabeça e dificuldades de dormir (apresenta muitas queixas hipocondríacas que perduram ao longo de seu acompanhamento).

No último encontro deste acompanhamento, a estagiária comunicou-lhe sua saída e indicou outra estagiária que a substituiria, caso ela desejasse dar continuidade ao trabalho. Parece ter aceitado, pois esta foi a sua queixa em tom agressivo no primeiro encontro, ou seja, a saída dos estagiários, às vezes vividas como abandono. Procurou-se explicar-lhe o motivo da saída, pois, em supervisão, sempre se pensa sobre os efeitos deste rodízio de estagiários. Ganho de experiência para estes, mas também perdas para ambos, o que exige a tarefa de elaboração.

\section{Psicose, sujeito e subjetividade no CAPS}

Em seus textos "Neurose e Psicose"14 e "A perda da realidade na neurose e na psicose", Freud $^{15}$ afirma que a principal diferenciação da 
psicose em relação à neurose consistiria na maneira de reconstruir a realidade que foi refutada. $\mathrm{O}$ que a psiquiatria denomina como começo da doença na psicose traz à tona, na verdade, uma tentativa de cura do sujeito, em que seu delírio representaria um esforço de reconstituição de seu eu. Portanto, diferentemente do médico que tenta suprimir o delírio psicótico, a conduta de uma prática psicanalítica da psicose envolve o acolhimento e a escuta deste sujeito, incluindo necessariamente suas alucinações e delírios.

Segundo Zenoni ${ }^{13}$, podemos dizer que a dita segunda clínica de Lacan retira da psicose qualquer imputação de déficit, classificando-a enquanto posição do sujeito, ou seja, "a psicose é um destino subjetivo, positivo". O que se propõe nesta clínica é acompanhar as soluções positivas e as invenções do sujeito, privilegiando o acompanhamento de seus diversos arranjos. Há que se ocupar uma posição de aprendizagem frente à psicose, tendo em vista estarmos lidando com um sujeito cheio de certezas. Como afirma Zenoni ${ }^{13}$, "é uma posição favorável para encontrar esse sujeito, sem alimentar uma posição intrusiva, persecutória de transferência”. Visa estabelecer uma desierarquização do saber prévio, de forma que as equipes dos serviços possam, no trabalho com a psicose, "encontrar o sujeito psicótico no processo do seu autotratamento e de poder nos apoiar sobre o que ele próprio inventa, seja para prolongar isso, seja para deslocá-lo"13.

Como nos referimos no início, ao criar a Casa das Palmeiras, Nise da Silveira foi pioneira na criação de um espaço extra-hospitalar para o tratamento da psicose. A partir de sua experiência no Centro Psiquiátrico Pedro II, Nise pôde desenvolver um trabalho precursor, rompendo com alguns estereótipos atribuídos à esquizofrenia, tais como embotamento afetivo, apagamento da afetividade, pobreza da ideação, demência. Seu longo percurso integrou a clínica com a pesquisa e o ensino, o que resultou em importante obra publicada e na criação do Museu Imagens do Inconsciente, que mantêm o acervo de trabalhos expressivos de psiquiatrizados mais importante do mundo, constituído pelos internos daquele Centro. A Casa das Palmeiras, ao ser caracterizada como um lugar de existência através da convivência diária, onde técnicos e 'hóspedes' participavam juntos e ativamente de suas atividades ${ }^{16}$, serve de referência para os atuais CAPS. Em re- lação à psicopatologia e ao diagnóstico psiquiátrico, Nise da Silveira ${ }^{17}$ afirma que:

Rótulos diagnósticos são, para nós, de significação menor, e não costumamos fazer esforços para estabelecê-los de acordo com classificações clássicas. Não pensamos em termos de doenças, mas em função de indivíduos que tropeçam no caminho de volta à realidade cotidiana.

Consequentemente, as concepções de normal e patológico ganham outro status. Desta forma, o estado patológico não recai mais como uma sentença ou um estigma, pois ele também revela a utilização de uma norma. Como afirma Tenório ${ }^{18}$, “(...) a psicose (...) é uma lógica, é um modo específico de constituição e funcionamento de um sujeito, e não um déficit que tem que ser medido ou corrigido na referência a um funcionamento normal (...)".

Há aí uma dimensão do sujeito que cria sentidos para si, o que deve ser levado em conta como essencial na clínica que se pretende fazer no CAPS.

\section{Considerações Finais}

Como diz Rinaldi ${ }^{19}$, com a tentativa de exclusão do louco e da loucura do convívio social, o chamado louco passou a ser "este estranho quase absoluto que, pelo espetáculo de sua alteridade, coloca em questão a 'normalidade' de que cada um é supostamente portador."

$\mathrm{O}$ asilo, portanto, foi assimilado ao lugar da loucura e do louco, o seu lócus natural, "lugar de louco é no hospício", diz o refrão popular. Como afirma Berlinck ${ }^{20}$, o pathos é próprio do humano, está no cerne da experiência subjetiva. E ainda com Bastide ${ }^{21}$, podemos dizer que, "se o louco traz em si a humana condição, o homem traz em si o terreno em que a loucura se enraíza". Se o movimento de oposição ao hospício assumiu o refrão da luta anti-manicomial (utopia anti-manicomial $)^{22}$, isso se deve a este lugar que o caracterizou como "violento, de exclusão, de sonegação e mortificação das subjetividades". Contra estas condições é que se afirmaram as lutas de transformação da realidade da assistência no Brasil e também em outros países, resultando no projeto da Reforma Psiquiátrica Brasileira. 
Em nossa experiência, as mudanças que levaram à criação do CAPS a partir do HD significaram a ampliação das atividades e de formas de cuidado. A concretização de um verdadeiro trabalho de equipe, num nível bastante avançado em relação ao anterior, além de condições materiais e espaciais muito melhores, faz do CAPS um dispositivo articulado ao espírito da Reforma. O exemplo de Maria demonstra que, se ela e outros frequentadores sentiram-se temerosos e inicialmente mais inquietos, ansiosos com a mudança, com o trabalho de inserção, ambientação e convivência no novo espaço, os benefícios do CAPS podem ser observados.

Como no caso de Maria, o acompanhamento terapêutico contribui para o desenvolvimento de laços sociais e afetivos e favorece a capacidade pragmática, contribuindo para a autonomia daqueles que a perderam ou não a desenvolveram. $\mathrm{O}$ programa terapêutico não visa tornar o psicótico altamente articulado e normal, mas acompanhá-lo em seu percurso, buscando um meio termo entre a posição singular do sujeito frente às exigências do mundo e os meios que ele cria para estar aí.

Esta possibilidade de estar no mundo, na vida comum, ser visto como alguém que é capaz de se posicionar, de ter desejos e direitos, aparece nas falas dos frequentadores. Como na fala de Maria, a respeito de sua experiência no desfile de moda, "nunca pensei que um dia fosse ser aplaudida por alguém" (sic). Como também de João, que participa de um grupo de teatro que se apresenta em diversos espaços, dentro e fora do estado do Rio de Janeiro, que ao se apresentar em uma assembleia geral do serviço diz, "Bom dia, eu sou João, sou usuário do CAPS e artista" (sic), ao invés de se dizer paciente.

Esta experiência para os alunos de graduação, em especial a experiência de estágio em um centro de atenção psicossocial tem sido bastante importante para a aproximação, reflexão e conhecimento das questões psicopatológicas e principalmente dos dispositivos terapêuticos da Reforma Psiquiátrica. Vários ex-estagiários fizeram especializações na área, concursos e hoje são profissionais de muitos serviços da Rede Assistencial em saúde mental. Para finalizar, retomamos a fala de Estamira, homenagem a sua memória, pois faleceu recentemente, para contrapor a sedimentação e a naturalização dos pensamentos dominantes. Diz ela, "Se é mais inteligente o livro ou a sabedoria"... "Tudo que é imaginado tem, existe, é" (Em "Estamira", um filme documentário de Marcos Prado ${ }^{23,24}$.

\section{Nota dos autores}

Este texto é derivado da prática extensionista e do acompanhamento regular supervisionado de frequentadores do CAPS. A sua elaboração foi feita pelos autores em conjunto, a partir da relação com a paciente, das observações clínicas diárias e da bibliografia discutida durante a elaboração da prática clínica e dos relatórios e registros do caso.

\section{Contribuição dos autores}

Cintia M.de S. e Ademir Pacelli Ferreira participaram do desenvolvimento do projeto, da análise e interpretação dos dados e da elaboração do artigo.

\section{Referências}

1. TENÓRIO, F. A reforma psiquiátrica brasileira, da década de 1980 aos dias atuais: história e conceitos. História, Ciências, Saúde - Manguinhos, Rio de Janeiro, vol. 9, n. 1, p. 25-59 jan./abr. 2002.

2. FOUCAULT, M. História da loucura na Idade Clássica. São Paulo: Perspectiva, 1972.45 p.

3. BRASIL. Relatório Final da III Conferência Nacional de Saúde Mental. Brasília, 11 a 15 de dezembro de 2001. Brasília: Ministério da Saúde, 2002. Disponível em: <http:// portal.saude.gov.br/portal/arquivos/pdf/3_conferencia_nacional_saude_mental.pdf >. Acesso em: 03 de junho de 2010.

4. AMARANTE, P. Loucos pela vida: a trajetória da Reforma Psiquiátrica no Brasil. 2.ed. Rio de Janeiro: Fiocruz, 2009. $136 \mathrm{p}$.

5. BRASIL. Congresso Nacional. Lei 10.216/2001. Disponível em: <http://www.planalto.gov.br/ccivil_03/leis/ leis_2001/110216.htm>. Acesso em: 03 de junho de 2010.

6._._. Ministério da Saúde. Portaria n. ${ }^{\circ}$ 336/GM. Em 19 de fevereiro de 2002. Disponível em: <http://portal. saude.gov.br/portal/arquivos/pdf/Portaria\%20GM\%203362002.pdf>. Acesso em: 03 de junho de 2010.

7. Ministério da Saúde. Secretaria de Atenção à Saúde. Departamento de Ações Programáticas Estratégicas. Saúde mental no SUS: os centros de atenção psicossocial. Brasília: Ministério da Saúde, 2004. Disponível em: <http:// www.ccs.saude.gov.br/saude_mental/pdf/SM_Sus.pdf $>$. Acesso em: 03 de junho de 2010.

8._. Ministério da Saúde. Secretaria de Atenção à Saúde. DAPE. Coordenação Geral de Saúde Mental. Reforma psiquiátrica e política de saúde mental no Brasil. Documento apresentado à Conferência Regional de Re- 
forma dos Serviços de Saúde Mental: 15 anos depois de Caracas. OPAS. Brasília, novembro de 2005. Disponível em: <http://portal.saude.gov.br/portal/arquivos/pdf/ relatorio_15_anos_caracas.pdf $>$. Acesso em: 03 de junho de 2010.

9. LEAL, E.M.; DELGADO, P. Clínica e cotidiano: o CAPS como dispositivo de desinstitucionalização. In: GULJOR, A. P. (Org.). Desinstitucionalização da Saúde Mental: contribuições para estudos avaliativos. Rio de Janeiro: CEPESC: IMS/LAPPIS: ABRASCO, 2007, p. 137-154.

10. AMARANTE, P. A (Clínica) e a Reforma psiquiátrica. In: Amarante P., (Org). Archivos de saúde mental e atenção psicossocial. Rio de Janeiro: Nau Editora, p. 45-65. 2003.

11. FERREIRA, A. \& col. SZUCHMACHER, A. Assistência e Ensino na Instituição Psiquiátrica: Interfaces de uma Experiência Plural. Revista Psicologia para a América Latina, n. 5, p. 1-16. 2006.

12. TENÓRIO, F. Tratando a psicose nos Centros de Atenção Psicossocial. In: A psicanálise e a clínica da Reforma Psiquiátrica. Rio de Janeiro, Rios Ambiciosos, p. 119-154. 2001.

13. ZENONI, A. Psicanálise e Instituição - A Segunda clínica de Lacan. Abrecampos, Belo Horizonte, ano 1, n. 0, Junho. p. 20, 34, 42, 51. 2000.

14. FREUD, S. (1924). Neurose e Psicose. Rio de Janeiro: Imago Editora, 1977. (Edição Standard Brasileira das Obras Psicológicas Completas de Sigmund Freud, v. XIX).

15.

(1924). A perda da realidade na neurose e na psicose. Rio de Janeiro: Imago Editora, 1977. (Edição Standard Brasileira das Obras Psicológicas Completas de Sigmund Freud, v. XIX).
16. FERREIRA, Ademir Pacelli. Entre a internação e a vida externa: Um espaço de acolhimento, atividades e convivência. Revista Informação Psiquiátrica; n. 12, v. 3, p. 106110, 1993.

17. SILVEIRA, N. Crise e tentativas de mutação na psiquiatria atual. In: O mundo das imagens. São Paulo: Ática, p. 11-22, 1992.

18. TENÓRIO, F. A psicopatologia como elemento da atenção psicossocial. In: ALBERTI, Sonia; FIGUEIREDO, Ana Cristina (org.) Psicanálise e Saúde Mental: Uma Aposta. Rio de Janeiro: Ed. Companhia Freud, p. 55-75. 2006.

19. RINALDI, D. A ordem médica: a loucura como doença mental. In: Em Pauta. Revista da Faculdade de Serviço Social da UERJ, Rio de Janeiro, n. 13, p. 103-115, jul./ dez.1998.

20. BERLINCK, M. Psicopatologia Fundamental. São Paulo: Escuta, 2000. 116 p.

21. BASTIDE, R. Sociologia das Doenças Mentais. Lisboa, Biblioteca Universitária. Publicações Europa-América, 1968. $257 \mathrm{p}$

22. AMARANTE, P. O homem e a serpente. Rio de Janeiro: Fiocruz, $1996.10 \mathrm{p}$.

23. FRAGA, C. Reforma psiquiátrica e atenção psicossocial: uma experiência no Caps-Uerj. 2010. Monografia de graduação apresentada no Instituto de Psicologia da UERJ. Rio de Janeiro. 2010. $61 \mathrm{fls}$.

24. Estamira. Direção [de] Marcos Prado. Riofilme/Zazen Produções Audiovisuais. Brasil. 2006. 1 bobina cinematográfica (115 min), sonoro, color.

\begin{abstract}
The objective of this paper is to present some thoughts about the importance of the transition from hospital day (HD) to the form of Psychosocial Attention Center (CAPS). Through the internship experience in the design of outreach to the Psychiatry Unit (HD / CAPS), seeks to analyze the changes that have occurred as a result of this transition. We present a case of one person who frequents the HD and then the CAPS to illustrate the aspects of the experience of this change. It indicates some elements to reflect on the question of institutionalization and deinstitutionalization in the new devices mental health in Brazil. Finally, it points to the importance of training professionals to advance the political transformation of practices in mental health.
\end{abstract}

Keywords: Psychosocial Care; Deinstitutionalization; Treatment Plan; Clinical Case 